\title{
Novel signaling interactions between proteinase-activated receptor 2 and Toll-like receptors in vitro and in vivo
}

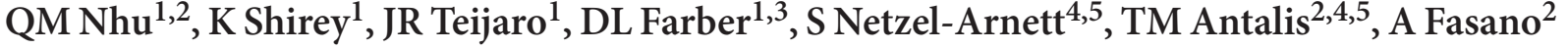 \\ and SN Vogel ${ }^{1,2}$
}

Toll-like receptors (TLRs) and proteinase-activated receptors (PARs) function as innate immune biosensors in mucosal

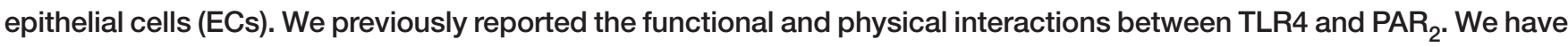
extended these findings herein by showing the cooperation between PAR ${ }_{2}$ and TLR2, TLR3, or TLR4 for activation of nuclear factor- $\mathrm{KB}$-dependent signaling in mucosal EC lines. In contrast, activation of $\mathrm{PAR}_{2}$ negatively regulated TLR3dependent antiviral pathway, blunting the expression of TLR3/interferon regulatory factor-3 (IRF-3)-driven genes, as well as activation of IRF-3 and STAT1. Consistent with these in vitro observations, $\mathrm{PAR}_{2}{ }^{-/-}$and TLR4 ${ }^{-/-}$mice, which were refractory to footpad edema induced by $\mathrm{PAR}_{2}$ agonist peptide, were protected from mouse-adapted $\mathrm{H} 1 \mathrm{~N} 1$ influenza $\mathrm{A}$ virus-induced lethality when compared to wild-type (WT) mice. These data support and extend our recently described, novel model of PAR ${ }_{2}$-TLR4 "receptor cooperativity" and highlight the complexity of signaling integration between heterologous innate immune biosensors.

\section{INTRODUCTION}

Pathogen recognition is a critical function of innate immunity. Distinct germline-encoded pattern-recognition receptors (PRRs) expressed on innate immune cells detect microbial structures and virulence factors, including microbial proteinases (reviewed in Gribar et al. ${ }^{1}$ and Vroling et al. ${ }^{2}$ ). Toll-like receptors (TLRs) and proteinase-activated receptors (PARs) represent two structurally distinct classes of transmembrane receptors that have key roles in the innate immune response to pathogens. For example, influenza A virus infection activates multiple PRRs, including TLR $3,{ }^{3,4}$ but also generates extracellular proteinases ${ }^{5,6}$ that could activate PARs.

"Classical" PRRs sense pathogen-associated molecular patterns (PAMPs), structural molecular motifs that are evolutionarily conserved and shared among members of a given microbial class (reviewed in Janeway and Medzhitov, ${ }^{7}$ Akira and Takeda, ${ }^{8}$ and Akira et al. ${ }^{9}$ ). In mouse and man, the TLRs represent a family of $>10$ single-transmembrane classical PRRs that detect chemically conserved microbial components, for example, lipopolysaccharide (LPS), lipopeptides, and RNA. Ligand engagement of TLR $\mathrm{N}$-terminal ectodomains induces receptor dimerization that brings the intracytoplasmic "Toll/interleukin-1 (IL-1) receptor resistance" (TIR) domains into close proximity. This interaction facilitates subsequent recruitment of TIR-domain-containing adapter proteins, kinases, and other signaling molecules to the "signaling platform" generated by the interacting TIR domains of the TLR dimer.

The innate immune system also senses proteolytic enzymes generated during infection through a family of "nonclassical" PRRs, for example, PARs. The PARs are a family of four 7-transmembrane, G protein-coupled receptors (7-TM GPCRs) that detect serine proteinases derived from pathogens and the host (reviewed in Steinhoff et al. ${ }^{10}$ and Ramachandran and Hollenberg ${ }^{11}$ ). $\mathrm{PAR}_{1}, \mathrm{PAR}_{3}$, and $\mathrm{PAR}_{4}$ are activated by thrombin; $\mathrm{PAR}_{2}$ mediates the cellular effects of trypsin and trypsin-like enzymes, including several microbial proteinases.

\footnotetext{
${ }^{1}$ Department of Microbiology and Immunology, University of Maryland, Baltimore (UMB), School of Medicine, Baltimore, Maryland, USA. ${ }^{2}$ Mucosal Biology Research Center, University of Maryland, Baltimore (UMB), School of Medicine, Baltimore, Maryland, USA. ${ }^{3}$ Department of Surgery, University of Maryland, Baltimore (UMB), School of Medicine, Baltimore, Maryland, USA. ${ }^{4}$ Department of Physiology, University of Maryland, Baltimore (UMB), School of Medicine, Baltimore, Maryland, USA. ${ }^{5}$ Center for Vascular and Inflammatory Diseases, University of Maryland, Baltimore (UMB), School of Medicine, Baltimore, Maryland, USA. Correspondence: SN Vogel (svogel@som.umaryland.edu) 
PAR-activating enzymes cleave each PAR irreversibly at a specific site in the extracellular $\mathrm{N}$-terminus to expose a tethered neo-ligand that binds to the second extracellular loop (ECL2) of each GPCR to trigger receptor activation. In this sense, the PARs function as a novel class of nonclassical PRRs that might serve as additional pathogen/tissue damage biosensors. Synthetic PAR agonist peptides (APs), corresponding to the hexapeptide sequences of the tethered neo-ligands of $\mathrm{PAR}_{1}, \mathrm{PAR}_{2}$, and $\mathrm{PAR}_{4}$, activate the native, uncleaved PARs nonenzymatically by binding directly to the corresponding PAR ECL2 to mediate signaling.

Proteinase-activated receptors and TLRs are distributed ubiquitously, yet strategically, in the body. Of the four PARs, $\mathrm{PAR}_{2}$ has been most extensively studied with respect to the inflammatory response to microbial exposure. $\mathrm{PAR}_{2}$ is expressed highly in the respiratory and gastrointestinal (GI) tracts on epithelial cells (ECs), endothelial cells, macrophages, and dendritic cells (DCs) (reviewed in Steinhoff et al. ${ }^{10}$ and Ramachandran and Hollenberg ${ }^{11}$ ). Exposure of human ECs to proteinases purified from certain pathogens activates $\mathrm{PAR}_{2}$ to induce antimicrobial and inflammatory responses. ${ }^{12-15}$ In mice, $\mathrm{PAR}_{2}$ deficiency reduces clearance of bacterial, parasitic, and fungal infections. ${ }^{16-18}$ Similar to PARs, TLRs are also expressed on ECs, endothelial cells, macrophages, and DCs in the airway and GI tract. In general, TLR2 and TLR4 recognize Gram-positive and Gram-negative bacteria, respectively; TLR3 detects double-stranded RNA (dsRNA) from viruses (reviewed in Akira and Takeda ${ }^{8}$ ). Experimentally, TLR2 is activated by synthetic di- or triacylated lipopeptides that mimic bacterial cell wall constituents. TLR3 is stimulated by the synthetic dsRNA analog, polyinosine-polycytidylic acid (poly I:C). TLR4 is triggered by Gram-negative bacterial LPS. Signals originating from independently engaged, heterologous receptors may converge synergistically or antagonistically to modify cellular responses to different exogenous stimuli (reviewed in Trinchieri and Sher ${ }^{19}$ and $\mathrm{O}^{\prime} \mathrm{Neill}{ }^{20}$ ). $\mathrm{PAR}_{2}$ activation delivers intracellular signals that intersect with TLR/IL-1R signaling pathways. ${ }^{21-24}$ We reported previously that $\mathrm{PAR}_{2}$ AP augmented LPS-induced IL-8 secretion synergistically in SW620 human colonic ECs. ${ }^{23}$ Our studies in HEK293T cells transfected with $\mathrm{PAR}_{2}$ and/or TLR4 revealed a novel mechanism of "receptor cooperativity" in which $\mathrm{PAR}_{2}$ AP-induced NF- $\mathrm{\kappa B}$ activation was synergistically enhanced by TLR4 coexpression. ${ }^{23}$ These findings were strengthened by the observation that $\mathrm{PAR}_{2}$ AP-induced NF- $\kappa \mathrm{B}$-dependent IL-1 $\beta$ mRNA expression in TLR4 ${ }^{-1-}$ macrophages was diminished. ${ }^{23}$ Moreover, an AP-dependent, physical interaction between $\mathrm{PAR}_{2}$ and TLR4 was shown in HEK293T cells by co-immunoprecipitation. ${ }^{23}$

Given that TLRs and PARs are concurrently present on mucosal ECs (reviewed in Vroling et al. ${ }^{2}$ ), we hypothesized that intracellular signaling pathways utilized by TLRs and $\mathrm{PAR}_{2}$ would converge either cooperatively or non-cooperatively when co-engaged. As the mucosal epithelium is the frontline innate immune barrier of the respiratory and GI tracts, we analyzed lung (A549) and colonic (SW620) ECs for responsiveness to stimulation of $\mathrm{PAR}_{2}$ and/or TLRs. Specifically, cellular responses to agonists of TLR2, TLR3, or TLR4 were examined to determine the potential effects of $\mathrm{PAR}_{2}$ activation on the inflammatory responses associated with bacterial and viral infections in mucosal ECs. Cooperation between $\mathrm{PAR}_{2}$ and TLR2, TLR3, or TLR4 for nuclear factor$\kappa \mathrm{B}(\mathrm{NF}-\kappa \mathrm{B})$-dependent IL-8 mRNA induction was observed. However, our data also revealed a novel role for $\mathrm{PAR}_{2}$ in the negative regulation of TLR3 antiviral pathway, leading to reduced expression of TLR3-, interferon (IFN) regulatory factor-3 (IRF3)-driven genes, and diminished activation of IRF-3 and signal transducer and activator of transcription 1 (STAT1). In vivo, both $\mathrm{PAR}_{2}^{-1-}$ and TLR4 ${ }^{-/-}$mice were highly refractory to footpad edema induced by $\mathrm{PAR}_{2} \mathrm{AP}$, and less susceptible to lethality following intranasal infection with a mouse-adapted $\mathrm{H} 1 \mathrm{~N} 1$ influenza A virus than wild-type (WT) C57BL/6J mice. Collectively, this study highlights the complexity of signaling integration between heterologous innate immune biosensors that result in modulation of host inflammatory responses.

\section{RESULTS}

We reported recently that $\mathrm{PAR}_{2} \mathrm{AP}$ synergized with the TLR4 agonist, LPS, to enhance IL-8 secretion in SW620 human colonic ECs. ${ }^{23}$ As $\mathrm{PAR}_{2}$ is expressed highly and strategically on ECs of the respiratory and GI tracts, we postulated that $\mathrm{PAR}_{2}$ might function as a novel, nonclassical PRR. We also hypothesized that cross talk between the two heterologous PRR classes, that is, $\mathrm{PAR}_{2}$ and TLR2, 3 , and 4, would modulate the inflammatory response.

\section{$\mathrm{PAR}_{\mathbf{2}}$ AP responsiveness in human mucosal EC lines}

Human lung (A549) and colonic (SW620) ECs were examined for responsiveness to $\mathrm{PAR}_{2} \mathrm{AP}$. Both responded rapidly to $\mathrm{PAR}_{2}$ AP with IL-8 mRNA induction that peaked rapidly at $0.5-1 \mathrm{~h}$ after stimulation (Figure 1a); SW620 ECs responded similarly, but somewhat less robustly than A549 ECs. PAR 2 AP-treated A549 ECs also expressed a broader array of proinflammatory mediator genes examined, for example, MIP- $3 \alpha$, tumor necrosis factor- $\alpha$ (TNF- $\alpha$ ), IL-6, IL-8, MIP- $2 \alpha$, MCP-1, and COX2 (Figure 1b) than SW620 ECs (data not shown). A549 and SW620 ECs responded to $\mathrm{PAR}_{2}$ AP with peak AP activities at $\sim 100$ vs. $\sim 300 \mu \mathrm{M}$, respectively (Figure 1c). A control, reverse peptide (RP) was inactive in both cell lines.

\section{Cooperative $\mathrm{PAR}_{2}-\mathrm{TLR}$ signaling integration in human mucosal EC lines}

A549 and SW620 ECs were next examined for responsiveness to TLR2, TLR3, or TLR4 agonists, that is, Pam2CSK4 (or P2C), poly I:C, or LPS, respectively, in the absence or presence of $\mathrm{PAR}_{2}$ AP. In both EC lines, PAR $_{2}$ AP enhanced IL-8 mRNA expression induced by these TLR agonists (Figure 2); a control RP had no effect. In A549 ECs, the effect of concurrent $\mathrm{PAR}_{2} \mathrm{AP}$ and LPS co-stimulation on IL-8 mRNA expression was additive (Figure 2a). However, in SW620 ECs, $\mathrm{PAR}_{2}$ AP potentiated LPS-induced IL-8 mRNA synergistically (Figure 2b). As for $\mathrm{PAR}_{2}$ and TLR2, cooperative signaling for IL-8 mRNA induction was detected in both EC lines (Figure 2). In addition, $\mathrm{PAR}_{2} \mathrm{AP}$, together with the TLR3 agonist, poly I:C, induced robust, synergistic augmentation of IL-8 mRNA levels in both EC lines (Figure 2). 

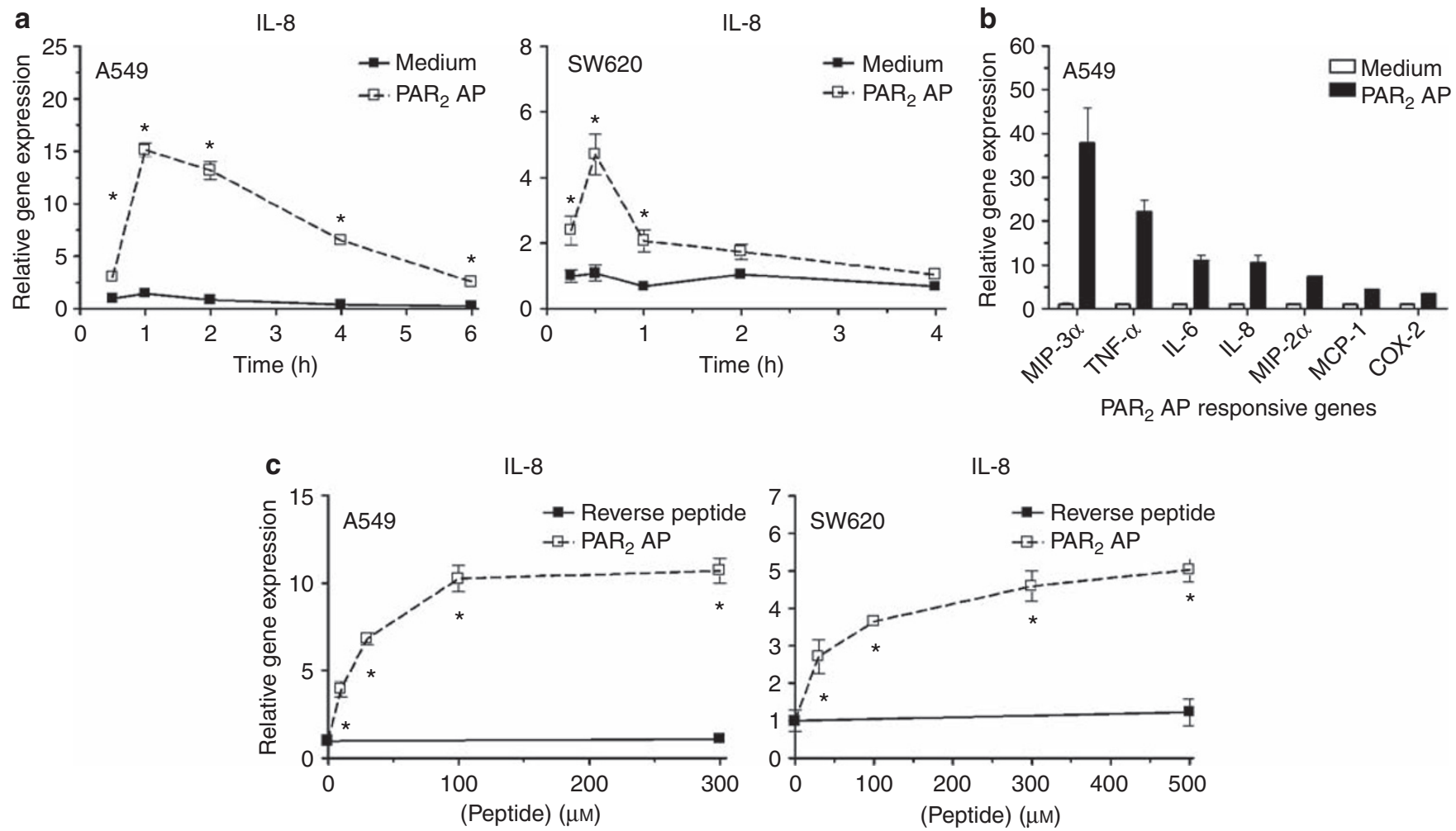

Figure 1 Responsiveness of human mucosal epithelial cell lines to proteinase-activated receptor $2\left(\mathrm{PAR}_{2}\right)$ agonist peptide (AP) stimulation. (a) $\mathrm{PAR}_{2}$ AP time course. Relative gene expression was analyzed by quantitative real-time PCR (qPCR). A549 cells were treated with medium or PAR 2 AP $(100 \mu \mathrm{m})$ over the indicated time points. Data are presented as the mean \pm s.d., representative of four separate experiments. SW620 cells were treated with medium or $\mathrm{PAR}_{2} \mathrm{AP}(300 \mu \mathrm{m})$ over the indicated time points. Data are presented as the mean \pm s.e.m. of four separate experiments. (b) Inflammatory mediator genes induced in PAR $\mathrm{P}_{2}$ AP-treated A549 cells. A549 cells were treated with medium or PAR $\mathrm{AP}_{2}(100 \mu \mathrm{M})$. Peak induction of genes examined occurred within $1-2 \mathrm{~h}$ after stimulation and is presented as the mean \pm s.e. $\mathrm{m}$. ( $n=2-6$ separate experiments). (c) PAR 2 AP concentration-response curves. A549 and SW620 cells were stimulated with $\mathrm{PAR}_{2}$ reverse-control peptide $(300$ or $500 \mu \mathrm{m}$, respectively) or the indicated concentrations of $\mathrm{PAR}_{2} \mathrm{AP}$ for $1 \mathrm{~h}$ or $30 \mathrm{~min}$, respectively. Relative gene expression is presented as the mean $\pm \mathrm{s}$.e.m. of two separate experiments for each cell line. ${ }^{*} p<0.05$.

\section{Cooperative and non-cooperative PAR $_{2}$-TLR3 signaling integration}

As the synergy between $\mathrm{PAR}_{2}$ and TLR3 was the strongest observed for any of the agonist combinations tested, we examined $\mathrm{PAR}_{2}-\mathrm{TLR} 3$ signaling interactions further. Poly I: C stimulates MyD88-independent signaling by recruiting the adapter protein, TRIF, to the TLR3 dimer. Although MyD88dependent signaling is predominantly associated with $\mathrm{NF}-\kappa \mathrm{B}$ activation, TRIF-dependent signaling results in the activation of IFN regulatory factor- 3 (IRF-3) and delayed NF- $\kappa \mathrm{B}$ activation (reviewed in Akira and Takeda ${ }^{8}$ and Akira et al. ${ }^{9}$ ). Although NF- $\kappa \mathrm{B}$ is most often associated with the induction of proinflammatory cytokines and chemokines, for example, IL- 8 and MIP-3 $\alpha$, IRF-3 is a potent transcriptional activator of many MyD88-independent genes, including IFN- $\beta$, IP-10, and RANTES. ${ }^{25,26}$ In both EC lines, $\mathrm{PAR}_{2} \mathrm{AP}$ induced mRNA expression of IL- 8 and MIP-3 $\alpha$, but did not stimulate the expression of IFN- $\beta$, IP-10, or RANTES mRNAs (Figure 3). $\mathrm{PAR}_{2}$ AP synergistically enhanced poly I:C-induced mRNA expression of IL-8 and MIP-3 $\alpha$ (Figure 3, top panels). In contrast, $\mathrm{PAR}_{2}$ AP significantly downregulated poly I:C-induced mRNA expression of IFN- $\beta$, IP-10, and RANTES (Figure 3). In A549 ECs, poly I:C-induced IFN- $\beta$ mRNA expression peaked at $\sim 2 \mathrm{~h}$ after stimulation (Figure 4); IP-10 mRNA expression was relatively delayed, consistent with its IFN- $\beta$ dependence. ${ }^{25-27} \mathrm{PAR}_{2}$ AP suppressed poly I:C-induced IFN- $\beta$ mRNA levels significantly at $2-4 \mathrm{~h}$ and markedly inhibited poly I:C-induced mRNA expression of IP-10 and RANTES at 3-6 h after stimulation. In contrast, $\mathrm{PAR}_{2} \mathrm{AP}$ enhanced poly I: C-induced IL- 8 and MIP- $3 \alpha$ mRNAs at all time points examined (Figure 4). Poly I:C, but not PAR 2 AP, induced TLR3 mRNA expression (Figure 4), ${ }^{26,28}$ and the delayed induction kinetics reflects its IFN- $\beta$ dependence. ${ }^{26}$ Consistent with its inhibitory effect on poly I:C-induced IFN- $\beta$ gene expression, $\mathrm{PAR}_{2}$ AP also inhibited poly I:C-induced TLR3 mRNA expression (Figure 4). Kinetic analysis of SW620 ECs stimulated with $\mathrm{PAR}_{2} \mathrm{AP}$ and/or poly I:C yielded similar results (data not shown). In contrast to its effects on poly I:C-induced IFN- $\beta$, IP-10, RANTES, and TLR3 mRNAs in A549 ECs, $\mathrm{PAR}_{2}$ AP enhanced mRNA expression of other TLR3-driven, NF- $\kappa \mathrm{B}$-regulated genes, that is, MCP-1, MIP- $2 \alpha$, TNF- $\alpha$, IL-6, and IL-1 $\beta$ (data not shown). Consistent with the mRNA data, $\mathrm{PAR}_{2}$ AP augmented poly I:C-induced IL- 8 and MIP$3 \alpha$ protein production synergistically, but suppressed poly I: C-induced IP-10 and RANTES secretion significantly in A549 ECs (Figure 5). 

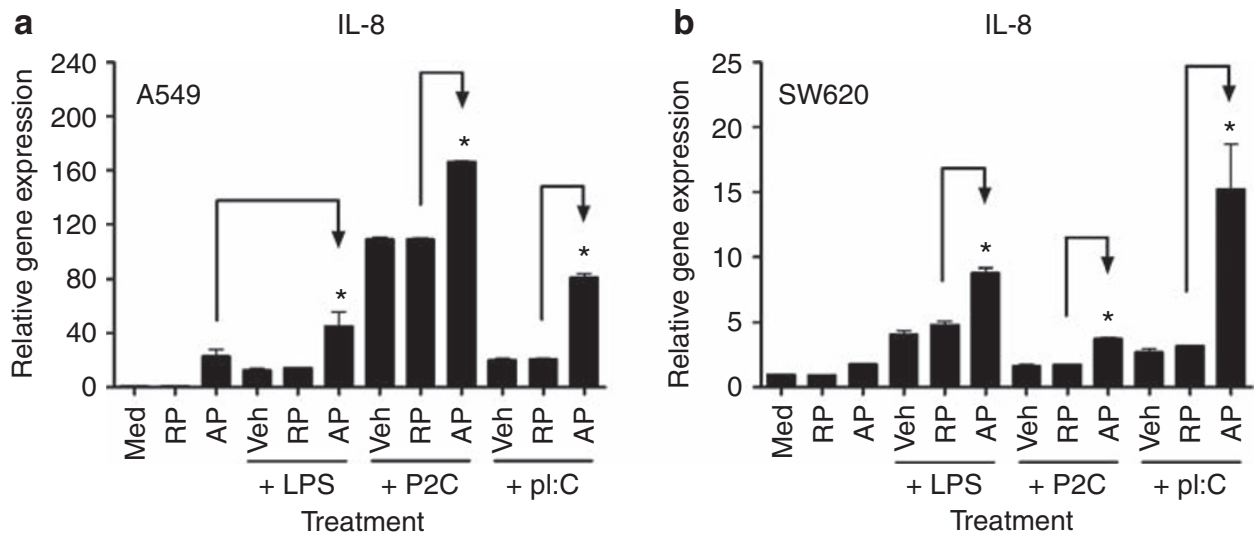

Figure 2 Proteinase-activated receptor $2\left(\mathrm{PAR}_{2}\right.$ ) agonist peptide (AP) augments Toll-like receptor (TLR)-induced interleukin-8 (IL-8) mRNA expression in human mucosal epithelial cell lines. Relative gene expression was analyzed by quantitative real-time PCR (qPCR). (a) A549 cells were treated with medium (Med), PAR reverse-control peptide (RP), or PAR 2 AP $(100 \mu \mathrm{m})$, in the absence or presence of lipopolysaccharide (LPS) $\left(1 \mu \mathrm{g} \mathrm{ml}{ }^{-1}\right)$, P2C $\left(0.1 \mu \mathrm{g} \mathrm{ml}^{-1}\right)$, or poly I:C (pl:C; $\left.100 \mu \mathrm{g} \mathrm{ml}^{-1}\right)$ for $3 \mathrm{~h}$. Data are presented as the mean \pm s.d., representative of three separate experiments. (b) SW620 cells were treated with medium (Med), PAR $\mathrm{R}_{2} \mathrm{RP}$, or PAR $\mathrm{PAP}_{2}(300 \mu \mathrm{M})$, in the absence or presence of LPS $\left(0.1 \mu \mathrm{g} \mathrm{ml}^{-1}\right)$, P2C $\left(0.1 \mu \mathrm{g} \mathrm{ml}^{-1}\right)$, or poly I:C $\left(\mathrm{pl}: \mathrm{C} ; 100 \mu \mathrm{g} \mathrm{ml}^{-1}\right.$ ) for $3 \mathrm{~h}$. Data are presented as the mean \pm s.d., representative of three separate experiments. Veh, vehicle; ${ }^{*} p<0.05$.

\section{PAR $_{2}$ AP differentially modulates TLR3-mediated activation of NF-KB and IRF-3}

Consistent with the observation that the NF- $\kappa \mathrm{B}$-responsive genes, for example, IL- 8 and MIP-3 $\alpha$, were significantly upregulated by $\mathrm{PAR}_{2}$ and TLR3 co-stimulation, NF- $\kappa \mathrm{B}$ p 65 activation (phospho-Ser536) was enhanced in A549 ECs co-stimulated with AP and poly I:C vs. AP or poly I:C alone (Figure 6a). This observation was supported by a significant reduction in the levels of the negative regulator of NF- $\kappa \mathrm{B}, \mathrm{I} \kappa \mathrm{B} \alpha$ (Figure $6 \mathbf{b}$ ). In contrast to augmented $\mathrm{NF}-\kappa \mathrm{B}$ activation, $\mathrm{PAR}_{2} \mathrm{AP}$ downregulated poly I:C-induced IRF-3 activation (phospho-Ser396) significantly (Figure 6c). Total IRF-3 levels were unaffected (Figures 6a-c). Experiments in HEK293T cells transiently transfected with $\mathrm{PAR}_{2}$, TLR3, and luciferase reporter constructs driven by promoters having either interferon-stimulated response element (ISRE) or NF- $\kappa \mathrm{B}$ binding sites showed similar results: $\mathrm{PAR}_{2}$ AP co-stimulation inhibited poly I:C-induced ISRE-luciferase activity, whereas AP and poly I:C co-treatments induced higher $\mathrm{NF}-\kappa \mathrm{B}$-luciferase reporter activity than AP or poly I:C alone (data not shown).

\section{PAR $_{\mathbf{2}}$ AP suppresses TLR3-induced STAT1 activation}

Poly I:C triggers the TLR3/IRF-3 pathway to induce the expression of IFN- $\beta$ that then binds to the type I interferon- $\alpha / \beta$ receptor (IFN- $\alpha / \beta \mathrm{R}),{ }^{25-27}$ resulting in the activation of several transcription factors, including STAT1. As PAR 2 AP suppressed poly I:C-induced IRF-3 activation and mRNA expression of IRF-3-dependent genes, including IFN- $\beta$, we predicted that AP would also suppress poly I:C-induced STAT1 activation. In A549 ECs, STAT1 Tyr701 phosphorylation (p-STAT1) was prominently induced at $\sim 3 \mathrm{~h}$ after stimulation with poly I:C, but not with $\mathrm{PAR}_{2} \mathrm{AP}$ at any time point examined; however, AP significantly inhibited p-STAT1 levels in poly I:C-treated ECs (Figure 6d). Total STAT1 levels were unaffected. Together, these data support the finding that $\mathrm{PAR}_{2}$ engagement can simultaneously augment TLR3-driven NF- $\kappa \mathrm{B}$ activation while inhibiting
TLR3-mediated IRF-3 responses, leading to downregulation of the second wave of signaling induced by the IFN- $\beta /$ IFN$\alpha / \beta \mathrm{R} / \mathrm{STAT} 1$ pathway.

We next asked whether PAR 2 AP would also inhibit IFN- $\beta$ induced STAT1 activation. In contrast to its inhibitory effect on poly I:C-induced STAT1 activation, $\mathrm{PAR}_{2}$ AP co-stimulation did not inhibit recombinant IFN- $\beta$ (rIFN- $\beta$ )-induced p-STAT1 levels in A549 ECs (Figure 6e).

\section{$\mathrm{PAR}_{2}{ }^{-/-}$and TLR4 ${ }^{-/-}$mice are protected from influenza-induced lethality}

As PAR $_{2}$ activation inhibited the TLR3/IRF-3 antiviral pathway in mucosal ECs, we hypothesized that $\mathrm{PAR}_{2}{ }^{-1-}$ mice would exhibit a de-repressed TLR3/IRF-3-mediated antiviral response and, thus, would exhibit increased protection against virus infection. Influenza A virus infection activates multiple PRRs, including MDA-5, RIG-I, and TLR3, , 3, but also generates significant tissue damage that produces extracellular proteinases, ${ }^{5,6}$ including elastase, ${ }^{5}$ that could activate $\mathrm{PAR}_{2}$ (reviewed in Vroling et al. ${ }^{2}$ ). WT C57BL/6J and $\mathrm{PAR}_{2}^{-1-}$ mice were infected intranasally with mouse-adapted $\mathrm{H} 1 \mathrm{~N} 1$ influenza virus, strain A/PR/8/34. At 200 p.f.u. (plaque-forming unit), $\sim 80 \%$ of WT mice died by day 14 after infection; in contrast, most of the $\mathrm{PAR}_{2}{ }^{-/-}$mice survived the infection (Figure 7a). At 600 p.f.u., all mice from both strains succumbed equally (data not shown). We reasoned that if $\mathrm{PAR}_{2}{ }^{-/-}$mice were resistant to influenza virus-induced lethality secondary to a de-repressed TLR3/IRF-3/IFN- $\beta$-mediated antiviral response, IFN- $\beta^{-1-}$ mice would exhibit the opposite phenotype. Although most of the $\mathrm{PAR}_{2}^{-/-}$mice survived the influenza infection (200 p.f.u.) vs. WT mice, all the IFN- $\beta^{-1-}$ mice died (Figure 7b). Taken together, these in vivo data support our observations in EC lines that $\mathrm{PAR}_{2}$ activation inhibits the antiviral response induced by innate immune biosensors, such as TLR3. The absence of $\mathrm{PAR}_{2}$ conferred a protective phenotype on influenza-infected mice. 
a
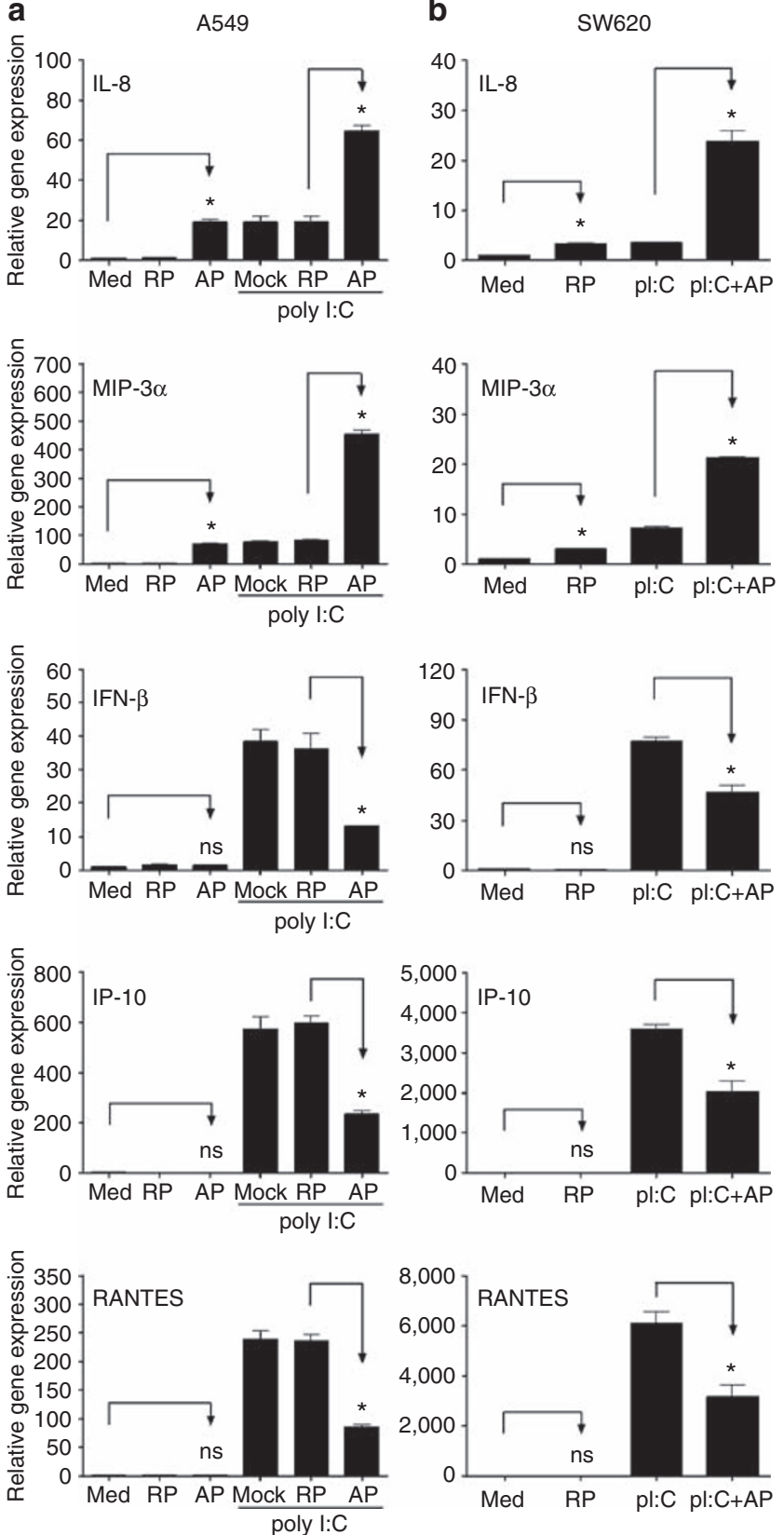

Figure 3 Proteinase-activated receptor $2\left(\mathrm{PAR}_{2}\right)$ agonist peptide (AP) differentially regulates Toll-like receptor 3 (TLR3) responses in human mucosal epithelial cell lines. Relative gene expression was analyzed by quantitative real-time PCR (qPCR). (a) A549 cells (left panels) were treated with medium (Med), $\mathrm{PAR}_{2}$ reverse-control peptide (RP), or $\mathrm{PAR}_{2}$ AP $(100 \mu \mathrm{m})$, in the absence or presence of poly I:C $\left(100 \mu \mathrm{g} \mathrm{ml}^{-1}\right)$ for $3 \mathrm{~h}$. Data are presented as the mean \pm s.d., representative of four separate experiments. (b) SW620 cells (right panels) were treated with medium (Med) or $\mathrm{PAR}_{2} \mathrm{AP}(300 \mu \mathrm{m})$, in the absence or presence of poly I:C $\left(100 \mu \mathrm{g} \mathrm{ml}^{-1}\right)$ for $3 \mathrm{~h}$. Data are presented as the mean $\pm \mathrm{s}$. d., representative of three separate experiments. ns, not significant; ${ }^{*} p<0.05$.

Previously, we showed receptor cooperativity between $\mathrm{PAR}_{2}$ and TLR4 in vitro. ${ }^{23}$ In HEK293T transfectants, PAR $_{2}$ engagement by its AP resulted in NF- $\kappa \mathrm{B}$ activation that was synergistically enhanced by the coexpression of TLR4. TLR4-mediated enhancement of $\mathrm{PAR}_{2}$ signaling was MyD88 dependent, whereas
$\mathrm{PAR}_{2}$ signaling in the absence of TLR4 was TRIF dependent. ${ }^{23}$ Conversely, $\mathrm{PAR}_{2}$ AP-treated TLR4 ${ }^{-/-}$macrophages exhibited significantly diminished expression of NF- $\kappa \mathrm{B}$-dependent IL-1 $\beta$ mRNA vs. WT macrophages. In the HEK293T transfection system, $\mathrm{PAR}_{2}$ AP induced a physical association between $\mathrm{PAR}_{2}$ and TLR4. ${ }^{23}$ We concluded from our earlier study that optimal PAR 2 signaling leading to $\mathrm{NF}-\kappa \mathrm{B}$ activation occurs when in complex with TLR4 and its adapter protein, MyD88. ${ }^{23}$

Given that optimal $\mathrm{PAR}_{2}$ signaling requires TLR $4,{ }^{23}$ and as $\mathrm{PAR}_{2}{ }^{-1-}$ mice were resistant to influenza-induced lethality, we hypothesized that TLR4 $4^{-/-}$mice would be similarly protected. Similar to $\mathrm{PAR}_{2}^{-/-}$mice, most of the TLR4 $4^{-/-}$mice survived $\mathrm{H} 1 \mathrm{~N} 1$ influenza A virus infection, under conditions in which most of the WT mice died (Figure 7c).

\section{TLR4 contributes to $\mathrm{PAR}_{\mathbf{2}}$-mediated inflammation in vivo}

To test further the hypothesis that $\mathrm{PAR}_{2}-\mathrm{TLR} 4$ receptor cooperativity occurs in vivo, we also used a well-characterized footpad edema model. ${ }^{29}$ Injection of $\mathrm{PAR}_{2} \mathrm{AP}$, but not saline or an inactive, control (reverse) peptide (RP), into the hind footpads of WT C57BL/6J mice rapidly induced edema that peaked at $1 \mathrm{~h}$ (Figure 8). Neither $\mathrm{PAR}_{2} \mathrm{AP}$ nor RP induced footpad edema in $\mathrm{PAR}_{2}{ }^{-1-}$ mice (Figure 8a). Compared to the WT response, $\mathrm{PAR}_{2} \mathrm{AP}$-induced footpad edema was significantly diminished in both TLR $4^{-/-}$and MyD88 ${ }^{-/-}$mice (Figures 8a and b). Together, these in vivo data further support our recently described novel model of $\mathrm{PAR}_{2}$-TLR4 receptor cooperativity ${ }^{23}$ in which optimal $\mathrm{PAR}_{2}$ signaling leading to an inflammatory response requires TLR4 and MyD88.

\section{DISCUSSION}

Signaling pathways coordinately triggered by distinct innate immune PRRs on activation by microbial components, for example, PAMPs, proteinases, have the potential to synergize with or antagonize one another to modulate an inflammatory response to infection. Results from our recent study showed that $\mathrm{PAR}_{2}$ and TLR4 synergized in vitro to augment a MyD88mediated, NF- $\kappa \mathrm{B}$-dependent inflammatory response. ${ }^{23}$ In this study, we have extended these original observations by studying signaling interactions between the classical PRRs, that is, TLR2, TLR3, and TLR4, and a nonclassical PRR, that is, PAR $_{2}$, in A549 and SW620 ECs derived from human respiratory and colonic mucosa, respectively. Our data presented herein support the conclusion that $\mathrm{PAR}_{2}$-TLR signaling integration drives "customized" inflammatory responses to combinatorial "danger" stimuli from the environment. We observed cooperative signaling convergence between $\mathrm{PAR}_{2}$ and TLR2, TLR3, or TLR4 for mRNA induction of NF- $\kappa \mathrm{B}$-dependent IL-8, a potent neutrophil chemoattractant; cooperation between $\mathrm{PAR}_{2}$ and TLR3 was highly synergistic. We also showed, for the first time, that $\mathrm{PAR}_{2}$ coactivation led to differential signaling outcomes in TLR3-stimulated mucosal ECs. We revealed a novel role for $\mathrm{PAR}_{2}$ in the negative regulation of TLR/IRF-3 antiviral pathway, leading to reduced expression of TLR3-, IRF-3-driven genes, for example, IFN- $\beta$, IP-10, and RANTES. Mechanistically, these $\mathrm{PAR}_{2}$-mediated differential effects on TLR3 signaling were traced to changes in 


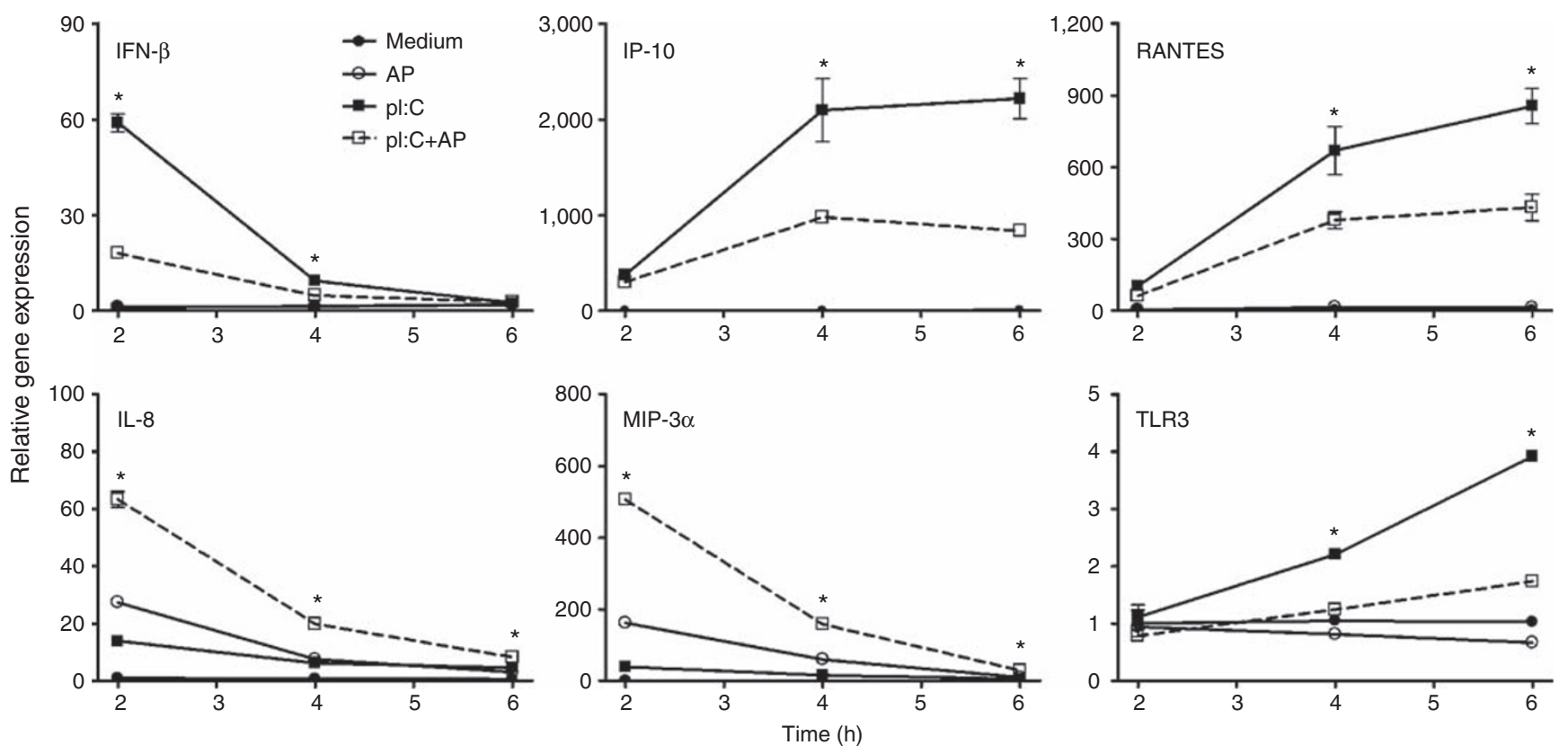

Figure 4 Kinetics of proteinase-activated receptor $2\left(\mathrm{PAR}_{2}\right)$ agonist peptide (AP)-mediated differential modulation of Toll-like receptor 3 (TLR3) responses in human lung epithelial cell line. A549 cells were treated with medium (closed circles), PAR ${ }_{2}$ AP (100 $\mu$ m; open circles), poly I:C (pl:C; $100 \mathrm{~g} \mathrm{ml}^{-1}$; closed squares), or both (open squares/dotted lines) over the indicated time. mRNA was subjected to quantitative real-time PCR (qPCR) analysis. Relative gene expression is presented as the mean \pm s.d., representative of three separate experiments. ${ }^{*} p<0.05$.

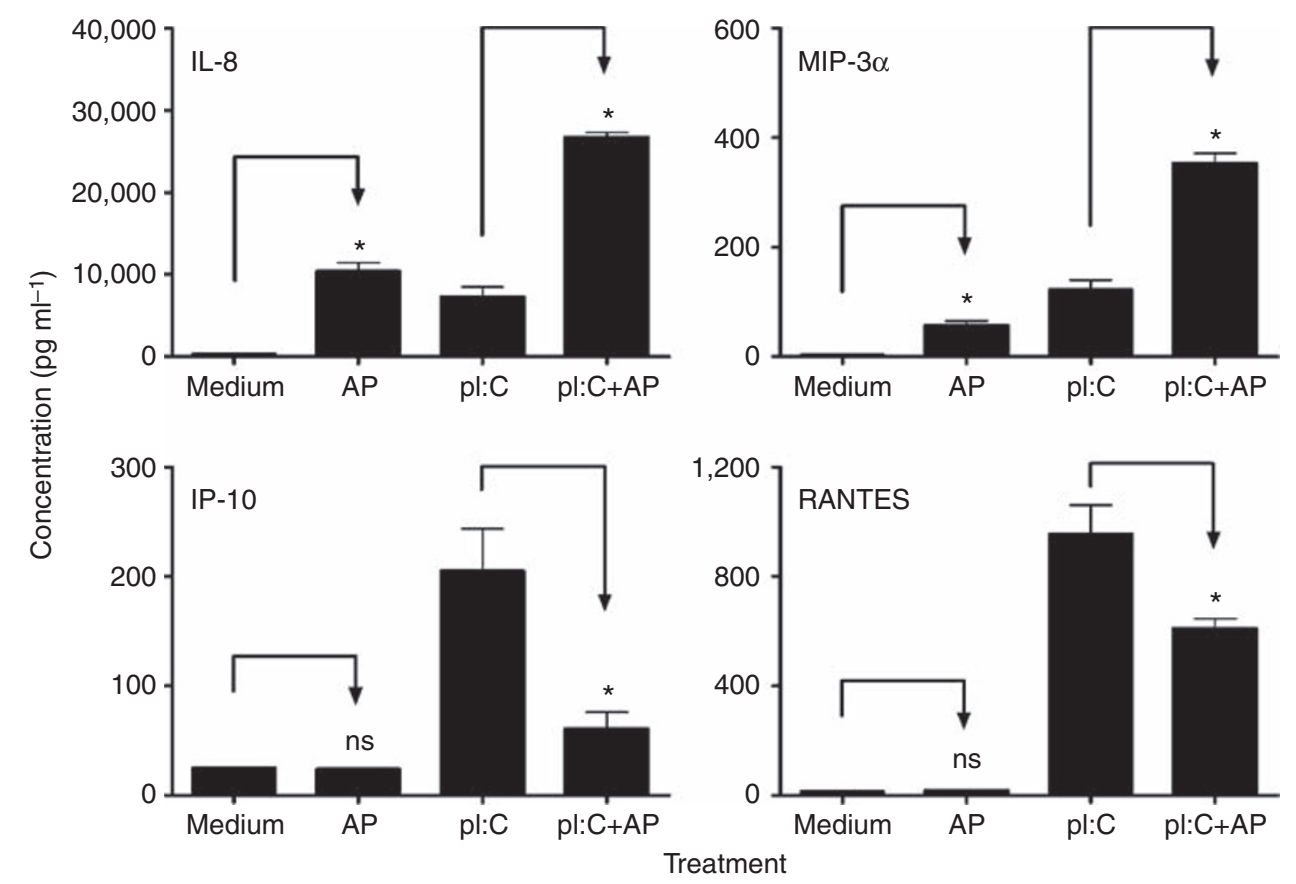

Figure 5 Proteinase-activated receptor $2\left(\mathrm{PAR}_{2}\right)$ agonist peptide $(\mathrm{AP})$ differentially regulates Toll-like receptor 3 (TLR3)-induced chemokine secretion in human lung epithelial cell line. In all, $8 \times 10^{5}$ A549 cells were seeded per well in 24-well plates overnight. Cells were treated with medium, PAR 2 AP $(200 \mu \mathrm{m})$, poly l:C (pl:C; $\left.100 \mu \mathrm{g} \mathrm{ml}^{-1}\right)$, or both for $24 \mathrm{~h}$ in $0.5 \mathrm{ml}$ volume. Supernatants were collected and analyzed for secreted chemokines by enzyme-linked immunosorbent assay (ELISA). Data are presented as the mean \pm s.d., representative of three separate experiments. ns, not significant; ${ }^{*} p<0.05$.

the level of activation of the transcription factors, NF- $\kappa \mathrm{B}$ and IRF-3. The inhibitory effect of $\mathrm{PAR}_{2}$ AP on TLR3-driven IRF-3 activation resulted in reduced IFN- $\beta$ expression and significant suppression of TLR3-inducible STAT1 activation. These in vitro observations in EC lines were supported by results showing that
$\mathrm{PAR}_{2}{ }^{-/-}$mice were more resistant to lethality following intranasal infection with $\mathrm{H} 1 \mathrm{~N} 1$ influenza A virus than WT C57BL/6J mice, whereas IFN- $\beta^{-/-}$mice were hypersusceptible.

During viral infection, RNA from viruses can be sensed by TLRs 3, 7, and 8, as well as the RNA helicase cytosolic sensors, 


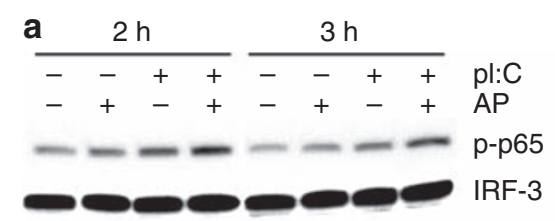

b

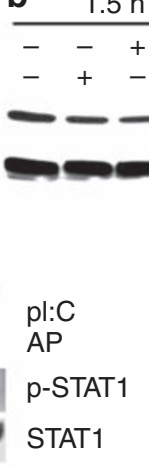

C

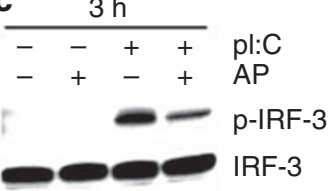

e

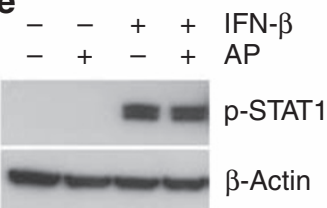

Figure 6 Effects of proteinase-activated receptor $2\left(\mathrm{PAR}_{2}\right)$ agonist peptide (AP) on Toll-like receptor 3 (TLR3) and interferon (IFN) $\alpha / \beta R$ signaling in human lung epithelial cell (EC) line. (a-d) PAR 2 AP differentially regulates TLR3 signaling in human lung EC line. A549 cells were treated with medium, PAR ${ }_{2}$ AP $(200 \mu \mathrm{m})$, poly I:C (pl:C; $\left.100 \mu \mathrm{gml}^{-1}\right)$, or both for the indicated time. Whole-cell lysates were subjected to SDS-polyacrylamide

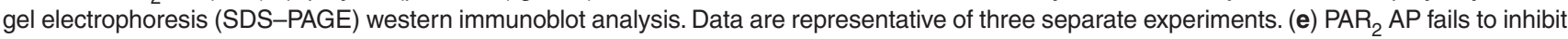
recombinant IFN- $\beta$ (rIFN- $\beta$ )-induced signal transducer and activator of transcription 1 (STAT1) phosphorylation in human lung EC line. A549 cells were treated with medium, PAR 2 AP $(200 \mu \mathrm{m})$, rIFN- $\beta\left(100 \mathrm{Uml}^{-1}\right)$, or both for $15 \mathrm{~min}$. Whole-cell lysates were subjected to SDS-PAGE western immunoblot analysis. Data are representative of three separate experiments.
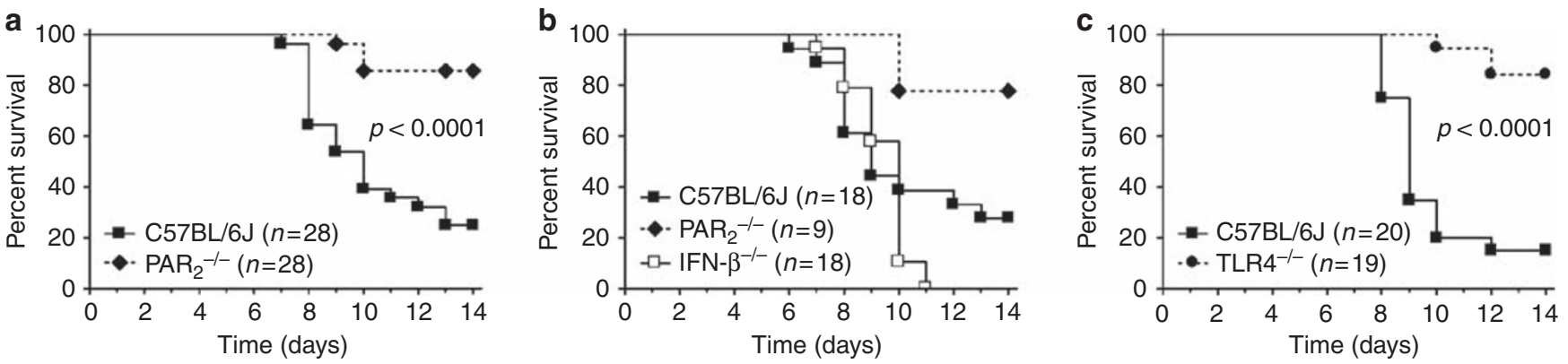

Figure 7 Susceptibility of mice to $\mathrm{H} 1 \mathrm{~N} 1$ influenza A virus-induced lethality. Mice were anesthetized with isoflurane and infected intranasally with $50 \mu \mathrm{l}$ mouse-adapted H1N1 influenza virus (A/PR/8/34; 200 p.f.u. (plaque-forming unit) per mouse) and survival monitored daily for 14 days. (a) Survival of $\mathrm{PAR}_{2}{ }^{-/-}$and wild-type (WT) C57BL/6J mice infected with influenza A virus. Data are the average of three separate experiments. (b) Survival of $\mathrm{PAR}_{2}^{-l-}$, interferon (IFN)- $\beta^{-/-}$, and WT C57BL/6J mice infected with influenza A virus. Data are the average of two separate experiments. (c) Survival of TLR4 ${ }^{-/-}$and WT C57BL/6J mice infected with influenza A virus. Data represent the average of two separate experiments. The total numbers of mice in each infection group are shown in parentheses.

RIG-I and MDA-5 (reviewed in Kawai and Akira ${ }^{30}$ ). We examined the cellular responses to TLR3 stimulation as a representative TLR-dependent antiviral pathway in mucosal ECs. Ligand-bound TLR3 activates several transcription factors, including IRF-3 and NF- $\kappa \mathrm{B} .{ }^{31}$ Ligand-activated TLR3 dimerizes, binds its sole adapter, TRIF, and recruits IкB kinase $\varepsilon(\mathrm{IKK} \varepsilon$ ) and TANK-binding kinase 1 (TBK1). ${ }^{32}$ In turn, IKK $/$ /TBK1 activates IRF-3 through C-terminal phosphorylation. The TLR3-TRIF complex also recruits receptor-interacting protein 1 (RIP1) to couple signaling to the IKK $\alpha / \beta / \gamma$ complex for NF- $\kappa B$ activation. ${ }^{33}$ Although activated NF- $\kappa \mathrm{B}$ translocates to the nucleus and induces transcription of many proinflammatory cytokine or chemokine genes, for example, IL-8, MIP-3 $\alpha$, phosphorylated IRF-3 homodimers translocate to the nucleus to induce transcription of type I IFNs and many other IRF-3-regulated genes, for example, IFN- $\beta$, IP- 10 , and RANTES. ${ }^{34}$ Induction of type I IFNs is critical for evoking the expression of additional antiviral genes through the IFN- $\alpha / \beta \mathrm{R} / \mathrm{STAT} 1$ signaling pathway. ${ }^{25-27}$

Both IRF- 3 and NF- $\kappa$ B are required for transcriptional activation of the potent antiviral protein, IFN- $\beta$ (reviewed in Kawai and Akira ${ }^{30}$ ). Although PAR 2 AP enhanced poly I:C-induced NF- $\kappa B$ activation, AP markedly inhibited poly I:C-driven IRF-3 activation, consistent with AP-mediated suppression of TLR3driven IFN- $\beta$ mRNA expression. The inhibitory effect of AP on the TLR3/IRF-3 signaling pathway appears to be very early, at the level of IKKE/TBK1 phosphorylation of IRF-3, rather than a result of altered IRF-3 protein stability. This is further supported by the observation that poly I:C-induced, but not rIFN- $\beta$-induced, phosphorylation of STAT1 was inhibited by concurrent stimulation of $\mathrm{PAR}_{2}$ by AP. The LPS-transducing receptor, TLR4, is the only other TLR that signals through the TRIF/IKKe/TBK1/IRF-3 pathway (reviewed in Akira and Takeda $^{8}$ ). In SW620 ECs, LPS-induced expression of IFN- $\beta$ and IP-10 mRNAs was attenuated significantly by PAR $_{2}$ AP co-stimulation (Supplementary Figure S1a online). In A549 ECs, PAR AP co-stimulation also inhibited LPS-induced IP-10 mRNA expression significantly (Supplementary Figure S1b). Taken together, these data suggest that $\mathrm{PAR}_{2}$ activation exerts a more generalized inhibitory effect on the TLR/TRIF, that is, TLR3/TRIF and TLR4/TRIF, signaling pathway. 

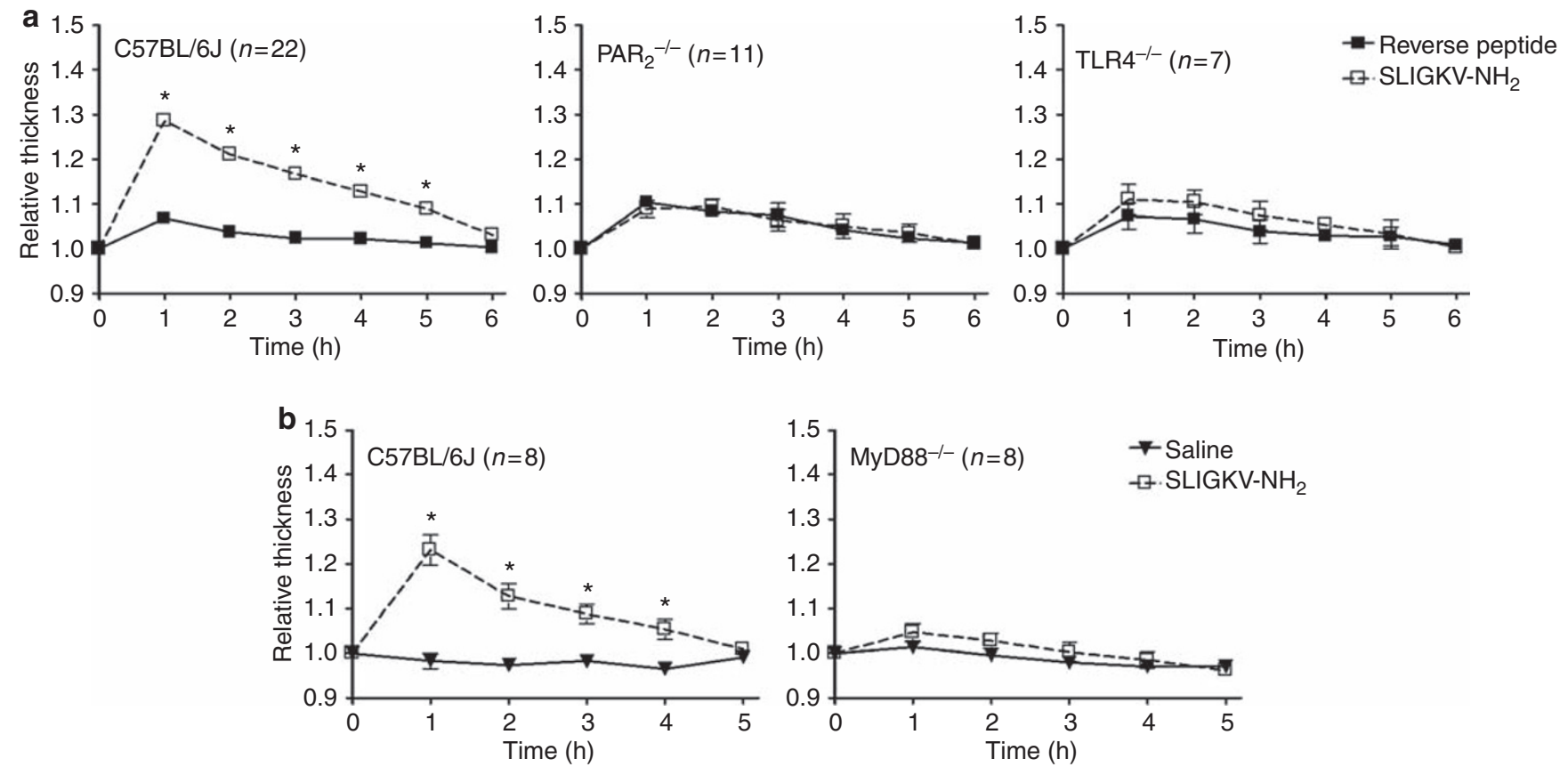

Figure 8 Toll-like receptor 4 (TLR4) contributes to proteinase-activated receptor 2 (PAR ( $_{2}$-mediated footpad inflammation in vivo. (a) Wild-type (WT) C57BL/6J, $\mathrm{PAR}_{2}{ }^{-1-}$, and TLR4 ${ }^{-/-}$mice were injected intraplantarly in the hindfoot with $\mathrm{PAR}_{2}$ agonist peptide $\left(\mathrm{SLIGKV}_{\mathrm{N}} \mathrm{NH}_{2}\right)$ or reverse-control peptide at $150 \mu \mathrm{g}$ per $30 \mu \mathrm{l}$. Footpad thickness was measured hourly for $6 \mathrm{~h}$ using an engineering caliper. Data are the mean \pm s.e.m. of two to six separate experiments. (b) WT C57BL/6J and MyD88 ${ }^{-/}$mice were injected intraplantarly in the hindfoot with PAR $_{2}$ agonist peptide $\left(\mathrm{SLIGKV}^{\mathrm{N}} \mathrm{NH}_{2}\right.$; $150 \mu \mathrm{g}$ per $30 \mu \mathrm{l}$ ) or saline. Footpad thickness was measured hourly for $5 \mathrm{~h}$ using an engineering caliper. Data represent the mean \pm s.e.m. of two separate experiments. ${ }^{*} P<0.05$. The total numbers of mice in each treatment group are shown in parentheses.

Consistent with previous reports attributing a positive, cooperative signaling outcome between $\mathrm{PAR}_{2}$ and TLRs, ${ }^{22-24}$ we showed positive cooperativity between $\mathrm{PAR}_{2}$ and TLRs at the level of NF- $\mathrm{KB}$ activation. The cooperative convergence of NF- $\kappa B$ signaling derived from these two distinct PRR families supports our contention of their proposed roles as biosensors of infection. Enhanced NF- $\kappa \mathrm{B}$ activation is predicted to be critical for optimal induction of inflammatory mediators, including the expression of chemokines and cytokines necessary for the recruitment and activation of circulating leukocytes to the nidus of infection. However, selective augmentation and suppression of cytokine/chemokine expression likely has an important role in the pathogenesis and persistence/clearance of a given infection. That $\mathrm{PAR}_{2}$ activation augmented TLR3-driven expression of some chemokines, for example, IL-8 and MIP-3 $\alpha$, yet suppressed the expression of others, for example, IP-10 and RANTES, suggests that proteinase-rich microenvironments might drastically alter the composition of infiltrating leukocytes and, thus, significantly alter the inflammatory outcome of an infection.

Under physiological conditions, extracellular proteinases are tightly regulated by many mechanisms, including the regulation of proteinase expression and their negative control by antiproteinases. Reduced expression of anti-proteinases and/or enhanced local levels of pathogen- and/or host-derived proteinases can lead to a dysregulated proteinase/anti-proteinase balance at anatomical sites where extracellular proteolysis is undesirable (reviewed in Antalis et al..$^{35}$ ). Given that $\mathrm{PAR}_{2}$ activation negatively regulated the TLR3/IRF-3 antiviral pathway, we speculated that in tissues in which both $\mathrm{PAR}_{2}$ and TLR3 are present, for example, the airway, disease processes with dysregulated and de-repressed extracellular $\mathrm{PAR}_{2}$-activating trypsin-like proteolytic activities might be more susceptible to infection with TLR3-triggering viruses such as influenza A. ${ }^{3,4}$ We confirmed this hypothesis by infecting WT C57BL/6 $\mathrm{J}_{\text {and }} \mathrm{PAR}_{2}{ }^{-1-}$ mice with mouse-adapted $\mathrm{H} 1 \mathrm{~N} 1$ influenza $\mathrm{A}$ virus that can activate TLR3 and also generates extracellular proteinases that can trigger $\mathrm{PAR}_{2}$. In support of our in vitro observations in EC cultures, in three separate experiments, $\mathrm{PAR}_{2}{ }^{-1-}$ mice were protected from challenge with influenza A virus. In contrast, IFN- $\beta^{-/-}$ mice were hypersusceptible to influenza virus-induced lethality. Taken together, both the in vitro and in vivo data support our model that $\mathrm{PAR}_{2}$ activation inhibits TLR/IRF-3 antiviral pathway; the absence of $\mathrm{PAR}_{2}$ conferred a protective phenotype in influenza-infected mice. The absence of $\mathrm{PAR}_{2}$ might also mitigate the NF- $\kappa \mathrm{B}$-mediated cytokine storm induced by influenza infection leading, in part, to the resistance of $\mathrm{PAR}_{2}{ }^{-1-}$ mice to influenza-induced lethality.

In contrast to our findings using 200 p.f.u. influenza virus per mouse, Khoufache et al. ${ }^{36}$ recently reported that $\mathrm{PAR}_{2}{ }^{-1-}$ mice were more susceptible to intranasal infection with cell culturepropagated $\mathrm{H} 1 \mathrm{~N} 1$ influenza $\mathrm{A} / \mathrm{PR} / 8 / 34$ virus (30-60 p.f.u. per mouse). Differences in infectious dose, method of virus propagation (i.e., cell culture vs. allantoic fluid of embyonated eggs), and housing conditions may account for the discrepancies between results reported by us and Khoufache et al. and warrant further investigation. It is unlikely, though, that our viral dose (200 p. f.u.) was less infectious because it killed $\sim 80 \%$ of the WT mice, whereas their dose of 30-60 p.f.u. was nonlethal in $\mathrm{PAR}_{2}^{+/+}$ 
mice. However, we hypothesize that different infectious doses used in the two studies (200 p.f.u. vs. 30-60 p.f.u.) perhaps led to differential levels of $\mathrm{PAR}_{2}$ receptor expression or activation that could potentially account for the opposite findings. The extent of tissue damage, the level of $\mathrm{PAR}_{2}$-activating enzymes generated, and the degree of $\mathrm{PAR}_{2}$ receptor activation secondary to influenza infection are likely to be different at the two viral doses. In support of this hypothesis, it has been shown that differential stimulus dosage, for example, low vs. high agonist concentrations, can result in opposite biological effects. For example, Eisenbarth et al. ${ }^{37}$ showed that low levels of LPS induced Thelper cell type 2 responses to an inhaled antigen, whereas high levels of inhaled LPS with the same antigen resulted in strong Th1 responses. The genetic backgrounds of the $\mathrm{PAR}_{2}{ }^{-/-}$mice used in the two studies were also different. The different genetargeted deletion approaches used to generate $\mathrm{PAR}_{2}{ }^{-1-}$ mice and the extent of genetic backcross may also have contributed to the opposite observations. ${ }^{38,39}$ In addition, $\mathrm{PAR}_{2}$ activation has been reported to exhibit opposite effects in other host inflammatory responses, ${ }^{40-43}$ and perhaps this is attributable to the balance of synergistic or antagonistic effects reported herein between $\mathrm{PAR}_{2}$ and activation of other PRRs by PAMPs that are concurrently present in the environment. Future studies will be necessary to determine how differences in experimental designs might have contributed to the different findings. Nevertheless, like $\mathrm{PAR}_{2}{ }^{-1-}$ mice, we observed that TLR4 ${ }^{-1-}$ mice were similarly protected from $\mathrm{H} 1 \mathrm{~N} 1$ influenza A virus infection, findings that are consistent with our recently described model of $\mathrm{PAR}_{2}-\mathrm{TLR} 4$ receptor cooperativity. Moreover, $\mathrm{PAR}_{2} \mathrm{AP}$ induced footpad edema in WT C57BL/6J mice that was absent in $\mathrm{PAR}_{2}{ }^{-1-}$ mice and significantly diminished in both TLR4 ${ }^{-/-}$and $\mathrm{MyD}^{-1-} 8^{-/-}$ mice. We also observed significantly diminished secretion of KC and MIP- $2 \alpha$ chemokines by TLR4 ${ }^{-1-}$ vs. WT C57BL/6J colonic intestinal tissues cultured ex vivo and treated with $\mathrm{PAR}_{2}$ AP (data not shown). Moretti et al. ${ }^{18}$ reported recently that $\mathrm{PAR}_{2}$ signaling in murine polymorphonuclear neutrophils depended on the presence of TLR4.

Interference of host innate antiviral defense by influenza virus is known to be achieved by the nonstructural NS1 viral protein, which dampens the induction of IRF-3-responsive antiviral genes, including IFN- $\beta{ }^{44}$ However, infection of host cells by orthomyxoviruses and paramyxoviruses can also be enhanced by host/pathogen-derived proteinases ${ }^{45}$ (and reviewed in Kido et al. $\left.{ }^{46}\right)$. For example, co-infection with Staphylococcus aureus strains that secrete trypsin-like serine proteinases enhances influenza virus infectivity significantly by mediating cleavage of viral fusion glycoproteins, for example, hemagglutinin. ${ }^{45}$ In this study, we have provided evidence for an additional mechanism by which host/pathogen-derived proteinases might diminish TLRmediated host antiviral response through the activation of $\mathrm{PAR}_{2}$. It is tempting to speculate that natural selection and host-virus co-evolution led to the utilization of proteinases for enhanced virus infectivity by simultaneously facilitating host-virus membrane fusion and interfering with host antiviral defense.

In summary, results from this study provide compelling data that suggest that regulating the extracellular proteinase/anti- proteinase balance might represent an effective therapeutic approach to controlling orthomyxovirus and paramyxovirus infections. The results from this study also represent a novel example of cooperative and non-cooperative signaling integration between heterologous PRRs of the innate immune system.

\section{METHODS}

Reagents, virus, cell culture, and mice. Human $\mathrm{PAR}_{2}$ AP, SLIGKV$\mathrm{NH}_{2}$, and an inactive control RP, VKGILS- $\mathrm{NH}_{2}$, were synthesized (>96\% purity) by Phoenix Pharmaceuticals (Belmont, CA). Proteinfree, phenol/water-extracted LPS from Escherichia coli strain K235 was purified as referenced. ${ }^{23}$ S-[2,3-bis(palmitoyloxy)-(2-RS)-propyl]-[R]-Cys-Ser-Lys $-\mathrm{OH}$ (Pam2CSK4 or P2C) and poly I:C (pI:C) were purchased from Invivogen (San Diego, CA). Human rIFN- $\beta$ 1a was purchased from PBL InterferonSource (Piscataway, NJ). Mouseadapted $\mathrm{H} 1 \mathrm{~N} 1$ influenza virus $(\mathrm{A} / \mathrm{PR} / 8 / 34)$ was purchased from American Type Culture Collection (ATCC) (Manassas, VA) and grown in the allantoic fluid of 10-day old embryonated chicken eggs (Charles River Laboratories, Wilmington, MA) as previously described. ${ }^{47}$ Human A549 lung and SW620 colonic ECs (ATCC) were propagated in Dulbecco's modified Eagle's medium (DMEM) or RPMI-1640 (CellGro, Herndon, VA), respectively. DMEM was supplemented with $10 \%$ heatinactivated fetal calf serum (FCS; Hyclone, Logan, UT), $100 \mathrm{U} \mathrm{ml}^{-1}$ penicillin, $100 \mu \mathrm{g} \mathrm{ml}^{-1}$ streptomycin, and $2 \mathrm{mM}$ L-glutamine. RPMI1640 received the same supplements, but with $2 \%$ heat-inactivated FCS. ECs were harvested from tissue culture flasks (Corning, Corning, NY) using CellStripper solution (CellGro) and seeded in 6-well plates at $4 \times 10^{5}$ (A549) or $1 \times 10^{6}$ (SW620) cells per well. Cells were allowed to rest for 2 days with a medium change on day 1 , and treated with agonists, as indicated. WT C57BL6/J mice and $\mathrm{PAR}_{2}{ }^{-1-}$ mice backcrossed onto a C57BL/6 background (N5) were purchased from The Jackson Laboratories (Bar Harbor, ME). TLR4 ${ }^{-/-}$and MyD88 ${ }^{-1-}$ mice $(\mathrm{N} \geqslant 8$ on a $\mathrm{C} 57 \mathrm{BL} / 6$ background), originally obtained from Dr Shizuo Akira (Osaka University, Osaka, Japan), and IFN- $\beta^{-1-}$ mice $(\mathrm{N} \geqslant 8$ on a C57BL/6 background), originally obtained from Dr Eleanor Fish (University of Toronto, Ontario, Canada), were bred at UMB. Mice were housed in a SPF barrier facility (UMB). Administration of AP or influenza to mice is described in the figure legends. All mice were age matched and used between 6-10 weeks of age. All experiments were conducted with institutional approval.

Preparation of total RNA and cDNA. Total RNA from EC cultures was extracted, and oligo(dT)-primed cDNA was synthesized as previously described. $^{28}$

qPCR. Quantitative real-time PCR (qPCR) primers (Table 1) were designed and synthesized as previously described. ${ }^{28} \mathrm{qPCR}$ was carried out on ABI Prism 7500 Fast Real-time PCR System (Applied Biosystems, Foster City, CA) in a $25 \mu \mathrm{l}$ reaction containing $20 \mathrm{ng}$ cDNA, $0.3 \mu \mathrm{M}$ each of sense/anti-sense primers, and $12.5 \mu \mathrm{l}$ of Fast SYBR Green Master Mix (Applied Biosystems) under the manufacturer's pre-set thermal conditions: $20 \mathrm{~s}$ at $95^{\circ} \mathrm{C}, 40$ cycles of $3 \mathrm{~s}$ at $95^{\circ} \mathrm{C}$ and $30 \mathrm{~s}$ at $60^{\circ} \mathrm{C}$, followed by a dissociation stage. Relative gene expression was calculated using the $2^{-\Delta \Delta \mathrm{Ct}}$ method as previously referenced, ${ }^{28}$ with hypoxanthine guanine phosphoribosyltransferase as the housekeeping gene.

Western analysis. A549 cells were seeded at $8 \times 10^{5}$ cells per well in 6-well plates and allowed to rest for 3 days, with a medium change on day 1 . After treatment, whole-cell lysates were collected, processed, resolved by gel electrophoresis, transferred to polyvinylidene difluoride membranes, probed with antibodies, and target protein bands detected as previously described. ${ }^{28}$ Primary and horseradish peroxidase-conjugated secondary antibodies used in this study were purchased from Cell Signaling Technology (Danvers, MA) and used at 1:1,000 and 1:2,000 dilutions, respectively. 
Table 1 Primer sequences of human genes examined by quantitative real-time PCR

\begin{tabular}{|c|c|}
\hline Target gene & Primer sequence \\
\hline HPRT & $\begin{array}{l}\text { 5'-CAAGCTTGCTGGTGAAAAGGAC-3' (S) } \\
\text { 5'-GTCAAGGGCATATCCTACAACAAA-3' (AS) }\end{array}$ \\
\hline IL-8 & $\begin{array}{l}\text { 5'-ATAAAGACATACTCCAAACCTTTCCAC-3' (S) } \\
\text { 5'-AAGCTTTACAATAATTTCTGTGTTGGC-3' (AS) }\end{array}$ \\
\hline MIP-3 $\alpha$ & $\begin{array}{l}\text { 5'-GCGGCGAATCAGAAGCA-3' (S) } \\
\text { 5'-GGCCAGCTGCCGTGTG-3' (AS) }\end{array}$ \\
\hline IFN- $\beta$ & $\begin{array}{l}\text { 5'-GGCAATTGAATGGGAGGCT-3' (S) } \\
\text { 5'-GGCGTCCTCCTTCTGGAACT-3' (AS) }\end{array}$ \\
\hline IP-10 & $\begin{array}{l}\text { 5'-TGACTCTAAGTGGCATTCAAGGAG-3' (S) } \\
\text { 5'-TTTTTCTAAAGACCTTGGATTAACAGG-3' (AS) }\end{array}$ \\
\hline RANTES & $\begin{array}{l}\text { 5'-TTTGCCTACATTGCCCGC-3' (S) } \\
\text { 5'-TTTCGGGTGACAAAGACGACT-3' (AS) }\end{array}$ \\
\hline TNF- $\alpha$ & $\begin{array}{l}\text { 5'-CCCAGGGACCTCTCTCTAATCA-3' (S) } \\
\text { 5'-GCTTGAGGGTTTGCTACAACATG-3' (AS) }\end{array}$ \\
\hline IL-6 & $\begin{array}{l}\text { 5'-GTAGCCGCCCCACACAGA-3' (S) } \\
\text { 5'-CATGTCTCCTTTCTCAGGGCTG-3' (AS) }\end{array}$ \\
\hline $\mathrm{IL}-1 \beta$ & $\begin{array}{l}\text { 5'-AAATACCTGTGGCCTTGGGC-3' (S) } \\
\text { 5'-TTTGGGATCTACACTCTCCAGCT-3' (AS) }\end{array}$ \\
\hline MIP-2 $2 \alpha$ & $\begin{array}{l}\text { 5'-CGCCCAAACCGAAGTCAT-3' (S) } \\
\text { 5'-GATTTGCCATTTTTTCAGCATCTTT-3' (AS) }\end{array}$ \\
\hline MCP-1 & $\begin{array}{l}\text { 5'-ACTCTCGCCTCCAGCATGAA-3' (S) } \\
\text { 5'-TTGATTGCATCTGGCTGAGC-3' (AS) }\end{array}$ \\
\hline cox-2 & $\begin{array}{l}\text { 5'-CCCATGTCAAAACCGAGGTG-3' (S) } \\
\text { 5'-CCGGTGTTGAGCAGTTTTCTC-3' (AS) }\end{array}$ \\
\hline
\end{tabular}

AS, antisense; COX-2, cyclooxygenase-2; HPRT, hypoxanthine guanine phosphoribosyltransferase; IFN- $\beta$, interferon- $\beta$; IL-1 $\beta$, interleukin-1 $\beta$; IL-6, interleukin-6; IL-8, interleukin-8; IP-10, 10 kDa interferon- $\gamma$-induced protein; MCP-1, monocyte chemotactic protein-1; MIP-2 $\alpha$, macrophage inflammatory protein-2 $\alpha$; MIP-3 $\alpha$, macrophage inflammatory protein-3 $\alpha$; RANTES, regulated upon activation, normal T-cell expressed, and secreted; S, sense; TNF- $\alpha$, tumor necrosis factor- $\alpha$.

Analysis of secreted proteins by ELISA. The concentrations of secreted proteins were determined by enzyme-linked immunosorbent assay (ELISA) by the Cytokine Core Laboratory (UMB).

Statistical analysis. Using GraphPad PRISM 4.0 (GraphPad Software, San Diego, CA), one-way analysis of variance (ANOVA) with Tukey's post-test or two-way ANOVA with Bonferroni post-test was performed to assess statistical significance $(P$-values $<0.05)$.

SUPPLEMENTARY MATERIAL is linked to the online version of the paper at http://www.nature.com/mi

\section{ACKNOWLEDGMENTS}

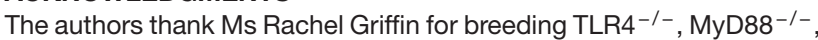
and IFN- $\beta^{-1-}$ mice, and Dr Prasad Rallabhandi for helpful discussion. This work was supported by the NIH Grants R37 Al-18797 (SNV), R01 DK048373 (AF), R01 HL084387, R01 DK081376, R01 CA098369 (TA), and R01 Al050632 (DF). QMN was supported, in part, by the NIH Training Grant (T32 Al-07540) and is currently supported by Al-18797 (SNV). JRT was supported by a minority supplement R01 Al50632S1. This work was carried out in partial fulfilment of the $\mathrm{PhD}$ requirements (QMN).

\section{DISCLOSURE}

The authors declared no conflict of interest.

\section{REFERENCES}

1. Gribar, S.C., Richardson, W.M., Sodhi, C.P. \& Hackam, D.J. No longer an innocent bystander: epithelial Toll-like receptor signaling in the development of mucosal inflammation. Mol. Med. 14, 645-659 (2008).

2. Vroling, A.B., Fokkens, W.J. \& Van Drunen, C.M. How epithelial cells detect danger: aiding the immune response. Allergy 63, 1110-1123 (2008).

3. Le Goffic, R. et al. Cutting Edge: Influenza A virus activates TLR3dependent inflammatory and RIG-I-dependent antiviral responses in human lung epithelial cells. J. Immunol. 178, 3368-3372 (2007).

4. Le Goffic, R. et al. Detrimental contribution of the Toll-like receptor (TLR)3 to influenza A virus-induced acute pneumonia. PLoS Pathog. 2, e53 (2006).

5. Buchweitz, J.P., Harkema, J.R. \& Kaminski, N.E. Time-dependent airway epithelial and inflammatory cell responses induced by influenza virus $\mathrm{A}$ PR/8/34 in C57BL/6 mice. Toxicol. Pathol. 35, 424-435 (2007).

6. Serkedjieva, J., Toshkova, R., Antonova-Nikolova, S., Stefanova, T., Teodosieva, A. \& Ivanova, I. Effect of a plant polyphenol-rich extract on the lung protease activities of influenza-virus-infected mice. Antivir. Chem. Chemother. 18, 75-82 (2007).

7. Janeway, C.A., Jr. \& Medzhitov, R. Innate immune recognition. Annu. Rev. Immunol. 20, 197-216 (2002).

8. Akira, S. \& Takeda, K. Toll-like receptor signalling. Nat. Rev. Immunol. 4, 499-511 (2004).

9. Akira, S., Uematsu, S. \& Takeuchi, O. Pathogen recognition and innate immunity. Cell 124, 783-801 (2006).

10. Steinhoff, M. et al. Proteinase-activated receptors: transducers of proteinase-mediated signaling in inflammation and immune response. Endocr. Rev. 26, 1-43 (2005).

11. Ramachandran, R. \& Hollenberg, M.D. Proteinases and signalling: pathophysiological and therapeutic implications via PARs and more. Br. J. Pharmacol. 153, S263-S282 (2008).

12. Sun, G., Stacey, M.A., Schmidt, M., Mori, L. \& Mattoli, S. Interaction of mite allergens Der p3 and Der p9 with protease-activated receptor-2 expressed by lung epithelial cells. J. Immunol. 167, 1014-1021 (2001).

13. Chung, W.O., Hansen, S.R., Rao, D. \& Dale, B.A. Protease-activated receptor signaling increases epithelial antimicrobial peptide expression. J. Immunol. 173, 5165-5170 (2004).

14. Kida, Y., Inoue, H., Shimizu, T. \& Kuwano, K. Serratia marcescens serralysin induces inflammatory responses through protease-activated receptor 2. Infect. Immun. 75, 164-174 (2007).

15. Dommisch, H. et al. Protease-activated receptor 2 mediates human betadefensin 2 and CC chemokine ligand 20 mRNA expression in response to proteases secreted by Porphyromonas gingivalis. Infect. Immun. 75, 4326-4333 (2007).

16. Moraes, T.J. et al. Role of PAR2 in murine pulmonary pseudomonal infection. Am. J. Physiol. Lung Cell. Mol. Physiol. 294, L368-377 (2008).

17. Devlin, M.G., Gasser, R.B. \& Cocks, T.M. Initial support for the hypothesis that $\mathrm{PAR}_{2}$ is involved in the immune response to Nippostrongylus brasiliensis in mice. Parasitol. Res. 101, 105-109 (2007).

18. Moretti, S. et al. The contribution of PARs to inflammation and immunity to fungi. Mucosal Immunol. 1, 156-168 (2008).

19. Trinchieri, G. \& Sher, A. Cooperation of Toll-like receptor signals in innate immune defence. Nat. Rev. Immunol. 7, 179-190 (2007).

20. O'Neill, L.A. When signaling pathways collide: positive and negative regulation of Toll-like receptor signal transduction. Immunity 29, 12-20 (2008).

21. Fyfe, M., Bergstrom, M., Aspengren, S. \& Peterson, A. PAR-2 activation in intestinal epithelial cells potentiates interleukin-1 $\beta$-induced chemokine secretion via MAP kinase signaling pathways. Cytokine 31, 358-367 (2005).

22. Ostrowska, E., Sokolova, E. \& Reiser, G. PAR-2 activation and LPS synergistically enhance inflammatory signaling in airway epithelial cells by raising PAR expression level and interleukin-8 release. Am. J. Physiol. Lung Cell. Mol. Physiol. 293, L1208-1218 (2007).

23. Rallabhandi, P. et al. Analysis of proteinase-activated receptor 2 and TLR4 signal transduction: a novel paradigm for receptor cooperativity. J. Biol. Chem. 283, 24314-24325 (2008).

24. Uehara, A., Hirabayashi, Y. \& Takada, H. Antibodies to proteinase 3 prime human oral, lung, and kidney epithelial cells to secrete proinflammatory cytokines upon stimulation with agonists to various Toll-like receptors, NOD1, and NOD2. Clin. Vaccine Immunol. 15, 1060-1066 (2008). 
25. Doyle, S. et al. IRF3 mediates a TLR3/TLR4-specific antiviral gene program. Immunity 17, 251-263 (2002).

26. Doyle, S.E., O'Connell, R., Vaidya, S.A., Chowoyle, E.K., Yee, K. \& Cheng, G. Toll-like receptor 3 mediates a more potent antiviral response than Toll-like receptor 4. J. Immunol. 170, 3565-3571 (2003).

27. Toshchakov, V. et al. TLR4, but not TLR2, mediates IFN- $\beta$-induced STAT $1 \alpha / \beta$-dependent gene expression in macrophages. Nat. Immunol. 3 , 392-398 (2002).

28. Nhu, Q.M., Cuesta, N. \& Vogel, S.N. Transcriptional regulation of lipopolysaccharide (LPS)-induced Toll-like receptor (TLR) expression in murine macrophages: role of interferon regulatory factors 1 (IRF-1) and 2 (IRF-2). J. Endotoxin Res. 12, 285-295 (2006).

29. Vergnolle, N., Hollenberg, M.D., Sharkey, K.A. \& Wallace, J.L. Characterization of the inflammatory response to proteinase-activated receptor-2 (PAR2)-activating peptides in the rat paw. Br. J. Pharmacol. 127, 1083-1090 (1999).

30. Kawai, T. \& Akira, S. Innate immune recognition of viral infection. Nat. Immunol. 7, 131-137 (2006).

31. Jiang, Z., Mak, T.W., Sen, G. \& Li, X. Toll-like receptor 3-mediated activation of NF- $\mathrm{KB}$ and IRF3 diverges at Toll-IL-1 receptor domaincontaining adapter inducing IFN- $\beta$. Proc. Natl. Acad. Sci. USA 101, 3533-3538 (2004).

32. Fitzgerald, K.A. et al. IKK $\varepsilon$ and TBK1 are essential components of the IRF3 signaling pathway. Nat. Immunol. 4, 491-496 (2003).

33. Meylan, E. et al. RIP1 is an essential mediator of Toll-like receptor 3-induced NF-kB activation. Nat. Immunol. 5, 503-507 (2004).

34. Yoneyama, M., Suhara, W., Fukuhara, Y., Fukuda, M., Nishida, E. \& Fujita, T. Direct triggering of the type I interferon system by virus infection: activation of a transcription factor complex containing IRF-3 and CBP/ p300. EMBO J. 17, 1087-1095 (1998).

35. Antalis, T.M., Shea-Donohue, T., Vogel, S.N., Sears, C. \& Fasano, A. Mechanisms of disease: protease functions in intestinal mucosal pathobiology. Nat. Clin. Pract. Gastroenterol. Hepatol. 4, 393-402 (2007).

36. Khoufache, K. et al. Protective role for protease-activated receptor-2 against influenza virus pathogenesis via an IFN- $\gamma$-dependent pathway. J. Immunol. 182, 7795-7802 (2009).
37. Eisenbarth, S.C., Piggott, D.A., Huleatt, J.W., Visintin, I., Herrick, C.A. \& Bottomly, K. Lipopolysaccharide-enhanced, toll-like receptor 4dependent Thelper cell type 2 responses to inhaled antigen. J. Exp. Med. 196, 1645-1651 (2002).

38. Damiano, B.P. et al. Cardiovascular responses mediated by proteaseactivated receptor-2 (PAR-2) and thrombin receptor (PAR-1) are distinguished in mice deficient in PAR-2 or PAR-1. J. Pharmacol. Exp. Ther. 288, 671-678 (1999).

39. Schmidlin, F. et al. Protease-activated receptor 2 mediates eosinophil infiltration and hyperreactivity in allergic inflammation of the airway. J. Immunol. 169, 5315-5321 (2002).

40. Kawabata, A. et al. The protease-activated receptor-2 agonist induces gastric mucus secretion and mucosal cytoprotection. J. Clin. Invest. 107, 1443-1450 (2001).

41. Cenac, N. et al. Induction of intestinal inflammation in mouse by activation of proteinase-activated receptor-2. Am. J. Pathol. 161, 1903-1915 (2002).

42. Afkhami-Goli, A. et al. Proteinase-activated receptor-2 exerts protective and pathogenic cell type-specific effects in Alzheimer's disease. J. Immunol. 179, 5493-5503 (2007).

43. Laukkarinen, J.M., Weiss, E.R., van Acker, G.J., Steer, M.L. \& Perides, G. Protease-activated receptor-2 exerts contrasting model-specific effects on acute experimental pancreatitis. J. Biol. Chem. 283, 20703-20712 (2008).

44. Geiss, G.K. et al. Cellular transcriptional profiling in influenza A virusinfected lung epithelial cells: the role of the nonstructural NS1 protein in the evasion of the host innate defense and its potential contribution to pandemic influenza. Proc. Natl. Acad. Sci. USA 99, 10736-10741 (2002).

45. Tashiro, M., Ciborowski, P., Klenk, H.D., Pulverer, G. \& Rott, R. Role of Staphylococcus protease in the development of influenza pneumonia. Nature 325, 536-537 (1987).

46. Kido, H., Murakami, M., Oba, K., Chen, Y. \& Towatari, T. Cellular proteinases trigger the infectivity of the influenza $A$ and Sendai viruses. Mol. Cells 9, 235-244 (1999).

47. Teijaro, J.R. et al. Costimulation modulation uncouples protection from immunopathology in memory $T$ cell responses to influenza virus. J. Immunol. 182, 6834-6843 (2009). 